\title{
Method for Multiple Portal Vein Infusions in Mice: Quantitation of Adenovirus-Mediated Hepatic Gene Transfer
}

BioTechniques 20:278-285 (February 1996)

\author{
Marie-Jeanne T.F.D. Vrancken \\ Peeters, Andre Lieber, James \\ Perkins and Mark A. Kay \\ University of Washington, \\ Seattle, WA, USA
}

\section{INTRODUCTION}

The liver is an attractive target organ for gene therapy since a wide variety of proteins are manufactured in the liver and many metabolic diseases result from an absence or deficiency of these hepatocyte-derived gene products. So far, two major approaches have been used for liver-related gene therapy in animal models in an attempt to correct genetic deficiencies. Ex vivo gene therapy involves transplantation of autologous retrovirus-transfected hepatocytes $(3,6)$. To date this is the only method of hepatic gene therapy that has been used in clinical trials (5).

Strategies for direct in vivo gene transfer include nonviral and viral vectors for delivery into the portal or peripheral vasculature (10). Recombinant retroviral vectors and recombinant adenoviral vectors are most widely used for hepatic gene transfer. The retrovirus is limited by the low titer, and thus, volume restriction limits the number of transducing particles that can be delivered $(2,9)$. Conversely, recombinant adenoviral vectors can be concentrated to high titer and can transduce nondividing cells at very high efficiencies (11). There are two major disadvantages of adenoviral vectors. The first is the associated immune response that limits the persistence of gene expression and the ability to perform secondary gene transfer $(1,17,20)$. A second potential problem is that after intravenous infusion, adenovirus, while highly hepatotrophic, infects most other tissues to varying degrees $(4,8,11,17)$.

The mouse is a valuable animal model for studying adenovirus-mediated gene therapy since it is small, and there are a large number of different in- bred and mutant strains for studying different metabolic genetic diseases (15). The use of the mouse as an animal model for hepatic gene transfer, however, has one disadvantage: the limited access to the portal vasculature. The anatomy of this small animal makes it difficult to perfuse the portal vein, and because of adhesions after portal vein injection, it has not been possible to perform multiple injections. Additionally, access to the portal vein is limited by ethical considerations of repeated survival procedures in animal research studies. The ability to perfuse the portal vasculature in a noninvasive manner would be useful for developing new technologies to increase the efficiency of both in vivo and ex vivo gene therapy protocols.

In this report we describe a new method that allows multiple portal vein injections in a mouse model by the placement of a permanent cannula. Subsequently, two questions were addressed using this new model. The first was to quantitate recombinant adenovirus within different tissues after either portal vein or peripheral tail vein infusion. Smith et al. (17) demonstrated similar levels of a plasma protein after administration of an adenoviral vector directly into the liver parenchyma or tail vein. They were able to quantitate the amount of adenovirus DNA in various tissues after peripheral vein administration of adenovirus. Other studies have used a less quantitative polymerase chain reaction (PCR) assay to determine a range of adenoviral DNA in different tissues after portal vein infusion (4). None of these studies directly compared adenovirus distribution in tissues after portal and peripheral vein infusion. 
The second question we addressed to our new model was whether the block to secondary gene transfer by production of neutralizing antibodies could be overcome by comparing transgene expression after a second direct adenovirus infusion into the portal vasculature vs. the peripheral vein.

\section{MATERIALS AND METHODS}

\section{Animals}

Female C57Bl/6 mice (The Jackson Laboratory, Bar Harbor, ME, USA), ages 5-6 weeks, were used in the described experiments. All studies were performed in accordance with the institutional guidelines at the University of Washington.

\section{Placement of a Permanent Portal Vein Cannula}

Mice were anesthetized with an intraperitoneal administration of 0.5 $\mathrm{mL}$ of $20 \mathrm{mg} / \mathrm{mL}$ Avertin (2,2,2-tribromoethanol; Aldrich Chemical, Milwaukee, WI, USA). A midline abdominal incision was made, and the skin was separated from the abdominal wall to create a subcutaneous pocket. The abdominal wall was opened at the linea alba, and the portal vein was exposed by displacing the intestinal duct.

Two different gas-sterilized tubes were used for the cannulation. An 8mm-long PE10 (0.011 in. i.d., 0.024 in. o.d.) polyethylene tube (Clay Adams, Parsippany, NJ, USA) was inserted into a silicone tube (0.02 in. i.d., 0.037 in. o.d.; Scientific Products Medical Grade Silicone Tubing; Baxter, IL, USA). The polyethylene tube was advanced about halfway $(4 \mathrm{~mm})$ past the orifice of the silicone tube and cut at the tip (with scissors) at about a 45 degree angle. Using a forceps, the sharp edge of the PE10 tube was used to penetrate the portal vein about $5 \mathrm{~mm}$ proximal to its bifurcation (Figure 1A). The catheter was gently advanced $4 \mathrm{~mm}$ (length of exposed PE 10 tube) and the forceps removed. The cannula was perfused with heparinized saline $(1 \mathrm{U} / \mathrm{mL})$ and then fixed in place with a drop of an adhesive (Histoacryl Blau; Braun Melsungen AG, Melsungen, Germany).

The intestinal duct was placed back to its original position, whereafter the cannula was tunneled through the abdominal wall, avoiding any blood vessels, and fixed with a 4.0 silk suture (David and Geck, Inc., American Cyanamid, Manati, PR, USA). After closure of the abdominal wall (continuous suture, 4.0 silk), the cannula was tied off at the distal end and placed subcutaneously in the previously created pocket (Figure 1B). Finally the skin

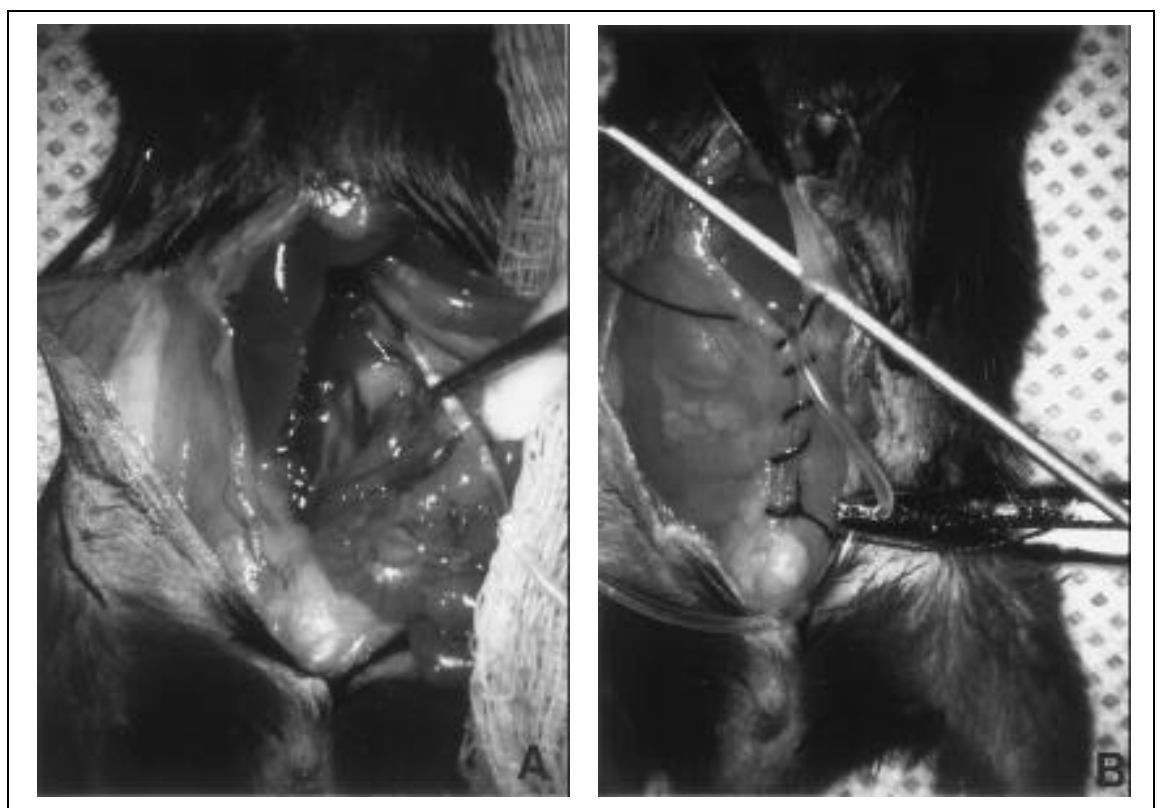

Figure 1. Surgical placement of a permanent silicone cannula into the portal vein in mice. (A) Demonstration of insertion of the proximal tip in the portal vein; (B) the distal end of the cannula is placed subcutaneously. was closed using a 4.0 silk suture.

After opening the skin at the proximal site of the already existing abdominal scar, the cannula can easily be pulled out and connected to a syringe pump to infuse either adenoviral vectors, retroviral vectors or in vitro-transduced hepatocytes.

\section{Adenovirus Production and Admin- istration}

Two recombinant adenoviral vectors were used, the Ad.RSV- $\beta$-gal (18) and the Ad/RSV-hAAT (7). The former virus produces $E$. coli nuclear localized $\beta$-galactosidase $(\beta$-gal) and the latter produces human $\alpha 1$-antitrypsin from transduced cells. The adenoviruses were propagated, purified, titered and screened for the absence of helper virus as described (1). The purified virus was stored in $10 \mathrm{mM}$ Tris- $\mathrm{HCl} \mathrm{pH} 8.0,1$ $\mathrm{mM} \mathrm{MgCl} 2,10 \%$ glycerol in aliquots at $-80^{\circ} \mathrm{C}$ and diluted freshly in serum-free Dulbecco's modified Eagle media (DMEM) (Life Technologies, Gaithersburg, MD, USA) prior to infusion. Mice received injections in either the tail vein or the portal vein by the portal vein cannula. For tail vein injections, 5 $\times 10^{9}$ plaque-forming units (pfu) of the purified adenovirus were diluted to 100 $\mu \mathrm{L}$ and injected into the tail vein in about $5 \mathrm{~s}$. For portal vein infusions, $5 \times$ $10^{9} \mathrm{pfu}$ were diluted to $200 \mu \mathrm{L}$ and infused over 5 to $10 \mathrm{~min}$.

\section{ONPG and DNA Blot Analysis}

Animals that received the Ad.RSV$\beta$-gal were sacrificed, and fresh liver, spleen, lung, heart, brain and ovary were analyzed for $\beta$-gal activity by $o$-nitrophenyl $\beta$-D-galactopyranoside (ONPG) assay, as previously described (1). A $\beta$-gal enzyme standard (Sigma Chemical, St. Louis, MO, USA) that was mixed with the lysate from corresponding tissues of a normal animal was used as a reference. The ONPG assay had a linear range from 0 to 2500 units. The $\beta$-gal activity from the livers of each mouse was analyzed individually. For the other tissues, equal amounts of tissue from each of the 4 mice were combined and analyzed together. For whole tissue DNA preparation, $0.1 \mathrm{~g}$ of tissue was homogenized in $3 \mathrm{~mL} 10 \mathrm{mM}$ Tris- $\mathrm{HCl}, 400 \mathrm{mM}$ $\mathrm{NaCl}, 2 \mathrm{mM}$ EDTA, $0.5 \%$ sodium dodecyl sulfate (SDS), $\mathrm{pH}$ 8.2. The cell 
lysate was incubated overnight with $200 \mathrm{U} / \mathrm{mL}$ proteinase K. After phenol chloroform extraction, $1.1 \mathrm{~mL}$ of saturated $\mathrm{NaCl}$ were added to the lysate. The supernatant was removed after centrifugation $(30 \mathrm{~min}, 10000 \times \mathrm{g}$ at room temperature) and the DNA precipitated with ethanol. The DNA was resuspended in $1 \times \mathrm{TE}(10 \mathrm{mM}$ Tris$\mathrm{HCl}, 1$ mM EDTA, $\mathrm{pH}$ 8.0).

Ten micrograms of DNA were digested with HindIII. The DNA was loaded onto a $0.7 \%$ agarose gel and, following electrophoresis, transferred to a Hybond ${ }^{\mathrm{TM}}$ (Amersham, Indianapolis, IN, USA) filter. The blot was hybridized sequentially with a randomprimed $[\alpha-32 \mathrm{P}]$ CTP-labeled $\quad 3.4-\mathrm{kb}$ $\beta$-gal DNA fragment from plasmid pCMV- $\beta$-gal (13) and the 2-kb HindIII/ EcoRI mouse metallothionein I gene fragment from plasmid mMMT-1 (16) in rapid hybridization buffer (Amersham) according to the manufacturer's protocol. The blot was washed in $0.1 \times$ standard saline citrate (SSC) at $65^{\circ} \mathrm{C}$ and exposed to X-ray film and/or analyzed by a Model 400S PhosphorImagerTM (Molecular Dynamics, Sunnyvale, CA, USA).

\section{Biochemical Analysis}

From mice that received the Ad/RSV-hAAT adenovirus, blood samples were obtained from the retroorbital plexus. Serum concentrations of human $\alpha 1$-antitrypsin were determined by an enzyme-linked immunosorbent assay (ELISA), using a human-specific antibody as previously described (9).

For the adenoviral neutralizing antibody assay, mouse serum samples were heat-inactivated at $55^{\circ} \mathrm{C}$ for $40 \mathrm{~min}$ and analyzed, following the protocol as described previously (1).

\section{RESULTS}

\section{Permanent Access into the Portal Vein}

A safe method for placement of a permanent portal vein cannula in mice was developed as described in the methods. The first series of experiments were designed to determine the safety and function of the cannula. Insertion of the catheter is shown in Figure 1. In an initial experiment, 20 mice received a cannula. In experi-

Table 1. $\beta$-gal Enzyme Analysis in Different Tissues After Administration of Ad.RSV- $\beta$-gal Adenovirus

\begin{tabular}{|lcccc|}
\hline & & \multicolumn{3}{c|}{ ONPG Activity in U/g Tissue } \\
\cline { 3 - 5 } Organ & & $\begin{array}{c}\text { Portal Vein } \\
\text { Injection }\end{array}$ & $\begin{array}{c}\text { Tail Vein } \\
\text { Injection }\end{array}$ & Control \\
\hline Liver & $\# 1$ & 2500 & 1004 & 0 \\
& $\# 2$ & 2104 & $>2500$ & \\
& $\# 3$ & 1764 & 1220 & 0 \\
Lung & $*$ & 456 & 656 & 0 \\
Heart & $*$ & 198 & 305 & 0 \\
Brain & $*$ & 50.7 & 128.6 & 0 \\
Ovary & $*$ & 1.16 & 1.58 & \\
Animals were infused with $0.5 \times 10^{10}$ pfu of Ad.RSV- $\beta$-gal and their organs were \\
removed after 3 days. Liver tissue was analyzed individually in each of the 4 \\
mice.
\end{tabular}

enced hands, mortality rate was less than 5\% in this and subsequent experiments. In some animals, methylene blue was infused to demonstrate patency and flow through the portal vasculature. In all cases the cannula remained patent for injection for at least 2 weeks after placement without perfusion with heparinized saline. Cannulas have been left in mice for up to a year without causing any detectable complications. Histological liver sections, obtained from 4 mice, 12 weeks after placement of the cannula were normal (not shown).

\section{Distribution of Adenovirus}

To determine the tissue distribution of recombinant adenovirus, mice were injected with $5 \times 10^{9}$ pfu of Ad.RSV- $\beta$ gal into the tail vein $(n=4)$ or the portal vein $(n=4)$, through the cannula. This dose of adenovirus has previously been shown to transduce $80 \%$ to $90 \%$ of hepatocytes (11). Three days after injection of adenovirus, animals were sacrificed and different tissues (liver, spleen, lung, heart, brain and ovary) were analyzed for $\beta$-gal enzymatic activity.

A high endogenous $\beta$-gal activity present in the spleen of normal mice precluded analysis in this tissue. Although there was some variation between animals, there was no significant difference in $\beta$-gal enzymatic activity

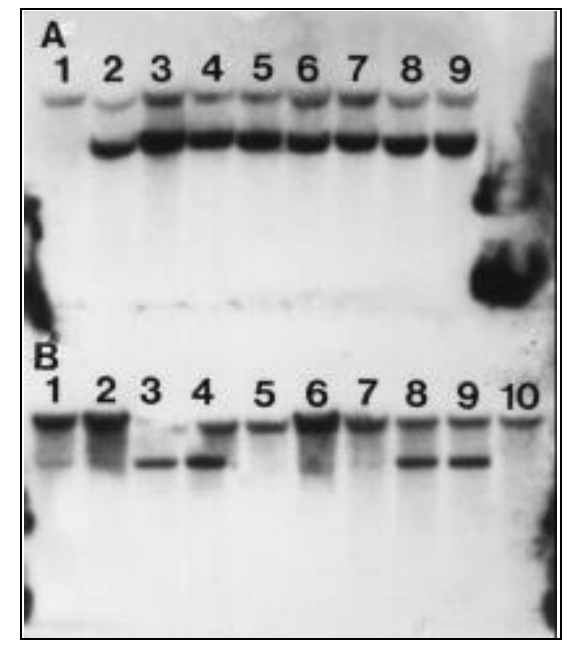

Figure 2. Recombinant adenoviral DNA detection in mice transduced with Ad.RSV- $\beta$-gal. Three days after administration of $0.5 \times 10^{10} \mathrm{pfu}$ of Ad.RSV- $\beta$-gal by portal vein or tail vein injection, total tissue DNAs were analyzed by Southern blot. $10 \mu \mathrm{g}$ of total DNA were digested with HindIII and loaded into each lane. The blot was hybridized with a ${ }^{32} \mathrm{P}$-labeled $\beta$-gal gene fragment. DNA from the livers of individual animals were analyzed: (A) control mouse, lane 1; tail vein infusion, lanes 2-5; portal vein infusion, lanes 6-9. DNA analysis of other tissues was performed after pooling an equal tissue mass from each of 4 animals; (B) tail vein infusions, lanes 1-5; portal vein infusions, lanes 6-10; heart, lanes 1 and 6; ovary, lanes 2 and 7; lung, lanes 3 and 8; spleen, lanes 4 and 9; brain, lanes 5 and 10 . The specific $\beta$-gal hybridization band is the lower one at $3.4 \mathrm{~kb}$. There is a nonspecific hybridization signal that is slightly larger that is also present in the control lane. Note the lower band in (B), lane 4 , is due to a small crack in the original gel. 
Table 2. Adenoviral Genome Quantitation in Tissues

\begin{tabular}{|c|c|c|c|}
\hline & & \multicolumn{2}{|c|}{ DNA Copy per Cell } \\
\hline \multicolumn{2}{|l|}{ Organ } & $\begin{array}{l}\text { Portal Vein } \\
\text { Injection }\end{array}$ & $\begin{array}{l}\text { Tail Vein } \\
\text { Injection }\end{array}$ \\
\hline \multirow[t]{4}{*}{ Liver } & $\# 1$ & 20 & 14 \\
\hline & \#2 & 22 & 28 \\
\hline & \#3 & 24 & 24 \\
\hline & $\# 4$ & 28 & 24 \\
\hline Spleen & * & 1.8 & 2.8 \\
\hline Lung & * & 3.0 & 2.0 \\
\hline Heart & * & 0.12 & 0.08 \\
\hline Brain & * & 0.02 & 0.01 \\
\hline Ovary & * & 0.02 & 0.08 \\
\hline \multicolumn{4}{|c|}{$\begin{array}{l}\text { The } \beta \text {-gal hybridization signals from the Southern blot (see Figure } 2 \text { ) were } \\
\text { quantitated and presented as genome copies per cell. For concentration mark- } \\
\text { ers, } 5,30 \text { and } 120 \mathrm{pg} \text { of } \mathrm{pCMV}-\beta \text {-gal plasmid ( } 30 \mathrm{pg} \text { represents } 1 \text { genome } \\
\text { equivalent) mixed with } 10 \mu \mathrm{g} \text { genomic DNA from a noninjected animal were } \\
\text { digested with HindlII. After quantification of signals by a phosphor imager, the } \\
\text { blot was rehybridized with a mouse metallothionein probe. This was used as an } \\
\text { internal control to adjust for the quantity of DNA in each lane and prior to calcu- } \\
\text { lating the number of adenovirus copies per cell. }\end{array}$} \\
\hline
\end{tabular}

in the livers of animals infused by tail vein or portal vein. The activity found in the liver of 4 different mice ranged between 450 and $>2500 \mathrm{U} / \mathrm{g}$ tissue (Table 1). Because of the relatively lower amount of gene expression in other tissues relative to the liver, each tissue from the 4 animals was pooled for analysis. The $\beta$-gal activity was detectable in all tissues with the lungs having the second greatest amount of activity, followed by the heart. Both the brain and the ovaries showed activities which were $1 / 1000$ of that obtained from the liver (Table 1). The amount of gene expression did not appear to be dependent on the route of adenovirus administration.

It is highly probable that variation in $\beta$-gal activity between tissues may in part result because of differences in gene regulation and may not directly reflect adenovirus copy number. Thus, to more accurately quantitate gene transfer to various tissues, the relative amount of DNA corresponding to the adenoviral genome was determined by genomic Southern blot analysis (Figure 2). Digestion of adenoviral DNA with HindIII produced the expected 3.4-kb $\beta$-gal DNA fragment. The relative amount of adenoviral DNA in all the li- ver samples was similar (Figure 2A), whereas marked differences were detected between different tissues (Figure 2B).

To quantitate the average number of adenoviral genome copies per diploid genome, samples containing varying genome equivalents of $\beta$-gal plasmid DNAs mixed with normal mouse genomic DNA were used as standards in the Southern blot (not shown). The blot was reprobed with a mouse metallothionen exon I DNA probe to adjust for small variations in DNA loading and transfer between lanes. A phosphor imager was used to quantitate the relative $\beta$-gal hybridization signal in each lane. The results are summarized in Table 2. The amount of adenoviral DNA averaged 14-28 copies per hepatocyte per animal. The hepatic adenovirus genome copies were $1 / 10$ to $1 / 1000$ less than in other tissues, and the relative quantity per tissue was in approximate agreement with the amount of $\beta$-gal enzyme activity. The lung and spleen had the second greatest amount of adenoviral DNA that was $1 / 10$ less than the liver. Importantly, no significant differences in tissue distribution were found after administration of adenovirus by portal vein or tail vein. 


\section{Repeat Adenovirus Injection}

The inability to transduce hepatocytes a second time with adenovirus is most likely related to humoral immunity $(1,17)$; thus, to determine whether infusion of virus just proximal to the liver in the portal vasculature would lead to secondary gene transfer, the permanent portal vein cannula was used for secondary adenovirus injection. Mice received a primary infusion of $5 \times 10^{9}$ pfu of Ad.RSV- $\beta$-gal into either the tail vein $(n=4)$ or the portal vein cannula $(n=4)$. All animals developed hightiter neutralizing antibodies directed against the adenovirus independent of the route of adenovirus administration that ranged between $1 / 64$ and 1/128. Three weeks hereafter, mice were exposed to a second administration of adenovirus. Ad/RSV-hAAT $\left(5 \times 10^{9}\right.$ pfu) virus was injected into the mice by the same route as the primary infusion, by the tail vein or the portal vein cannu- la. The antibody titers in all the animals measured 3 days later were greater than $1 / 1024$.

To assess the success of the second adenovirus injection, blood samples were obtained from the retro-orbital plexus and assayed for hAAT protein by ELISA. No hAAT $(<100 \mathrm{ng} / \mathrm{mL})$ was detected in the serum from any of the 8 mice that had previously been exposed to Ad.RSV- $\beta$-gal. In contrast, serum hAAT levels in previously naive control mice injected by means of the cannula or tail vein were in the range of 5000-10000 ng/mL. Thus, even direct secondary infusion of virus into the proximal portion of the portal vein was not sufficient to achieve secondary adenovirus-mediated gene transfer.

\section{DISCUSSION}

We report a new surgical technique to make the portal vasculature more accessible for hepatic gene therapy in the mouse by creating permanent access to the portal vein. This method allows for multiple injections directly into the portal vein without a second invasive procedure. All injections can be performed slowly (10-50 $\mathrm{min}$ ) by connecting the cannula to a syringe pump, allowing a greater volume to be perfused.

Using this new model, we addressed two questions for using adenoviral vectors for hepatic gene therapy. Administration of adenovirus into either the tail vein, inferior vena cava or the portal vein results in similar levels of gene expression $(7,17)$. In some previous studies, amount of transgene product was measured as a serum/plasma protein, and the proportion produced in the liver could not be quantitated. Recombinant DNA quantitation is a more accurate reflection of gene transfer, and in this study, 14-28 adenoviral DNA copies of adenovirus were detected per hepatocyte. This is in agreement with Smith et al. (17), who demonstrated 55 copies 
per cell when a twofold larger dose was administered by tail vein. Conversely, Fang et al. (4) reported 0.7 to 7 copies per mouse hepatocyte with viral delivery to the portal vein using a less quantitative PCR assay to establish adenovirus copy number. The lower copy number may have been due to the analysis performed one week after gene transfer, by which time gene expression had decreased. Assuming that there are $10^{8}$ hepatocytes per liver and that there are 20 adenoviral genomes per cell, then we estimate $40 \%$ of the adenovirus was taken up by liver. This is probably an underestimate since mouse hepatocytes may be polyploid (19). Our study clearly demonstrates that the amount of adenovirus in the liver is the same regardless of the route of administration.

The tissue distribution of adenovirus is an important safety consideration when such vectors are considered for clinical protocols. This study demonstrates that the distribution of vector into other tissues is not influenced by the route of administration. Both tail vein and portal vein injection result in transduction of other organs, including heart, brain and ovary, but with $1 / 100$ to $1 / 1000$ less vector per cell than liver. This study is in agreement with others that demonstrate that the spleen and lung contain the second greatest amount of vector, about $1 / 10$ less than liver $(4,17)$.

Adenovirus-mediated gene transfer leads to transient gene expression; for long-term treatment of genetic metabolic disorders, multiple injections are required. Previous studies reported that repeated tail vein injection failed to result in gene expression $(1,17)$. We now demonstrate that repeat injections into the portal vein did not result in detectable gene expression either. In this study both tail vein injection and portal vein injection led to the development of neutralizing antibodies against adenovirus that inhibited reinfection of hepato- cytes. Injection of a high dose of adenovirus into the portal vein, so that the virus reaches the liver parenchyma immediately, did not circumvent the immunological block against adenovirus. The reason for this result is not known but could be related to issues of firstpass uptake by the liver. Further studies are needed to address the mechanism.

Long-term access to the portal vein will be an attractive means by which to develop new methods for improving the efficiency of both nonvirus- (e.g., liposomes) and retrovirus-mediated in vivo/ex vivo hepatic gene therapy. Retrovirus-mediated in vivo gene therapy has the resulting advantage of permanent gene expression. However, this approach is limited by the amount of virus particles that one can infuse. The maximal titer of standard retrovirus is $10^{6}-10^{7}$ colony-forming units (cfu) per $\mathrm{mL}$. The volume that can be injected in the mouse is limited to $1 \mathrm{~mL}$ (about 2/3 of the total blood volume of a mouse) 
and results at best in a transduction efficiency of only $1 \%-2 \%(2,9)$. Recently we have developed new technologies using the portal vein cannula to give multiple doses of retrovirus (12).

For hepatocyte transplantation in the mouse as part of an ex vivo approach, the amount of hepatocytes that can be injected in the portal vein is limited. When injecting more than $5 \times 10^{5}$ cells in the portal vein, the mortality rate is $100 \%$ mainly due to pulmonary emboli and portal vein thrombosis. Less than $1 \%$ of the total liver mass can be replaced by transplanting this maximal amount of hepatocytes (14). By giving slow infusions of $2 \times 10^{6}$ hepatocytes 24 hours apart, it has been possible to transplant up to $4 \times 10^{6}$ hepatocytes (unpublished data). This will increase the range of transplantation studies that can be performed in mice.

The surgical implantation of a permanent cannula into the portal vein of mice will have applications for studying a number of different metabolic parameters outside of gene therapy that require portal vein access for multiple procedures.

\section{ACKNOWLEDGMENTS}

This work was supported in part by NIH Grant, DK 49022 and the Lucille P. Markey Charitable Trust. We thank R. Garcia for his technical advice. M.-J. T.F.D. V.P. was supported by the Dutch NWO Grant 901-01-096.

\section{REFERENCES}

1.Barr, D., J. Tubb, D. Ferguson, A. Lieber, A.J. Perkins and M.A. Kay. 1995. Strain related variations in adenovirally-mediated transgene expression in mouse hepatocytes in vivo: comparisons between immunocompetent and immunodeficient inbred strains. Gene Ther. 2:151-155

2.Branchereau S., D. Calise and N. Ferry. 1994. Factors influencing retroviral-mediated gene transfer into hepatocytes in vivo. Hum. Gene Ther. 5:803-808.

3.Chowdhury, J.R., M. Grossman, S. Gupta, N.R. Chowdhury, J.R. Baker and J.M. Wilson. 1991. Long-term improvement of hypercholesterolaemia after ex vivo gene therapy in LDLR-deficient rabbits. Science 254:18021805.

4.Fang, B., R.C. Eisensmith, X.H.C. Li, M.J. Finegold, A. Shedlovsky, W. Dove and S.L.C. Woo. 1994. Gene therapy for phenylketonuria: phenotypic correction in a genetically deficient mouse model by adenovirusmediated hepatic gene transfer. Gene Ther.
1:247-254.

5.Grossman, M., S.E. Raper, K. Kozarsky, E.A. Stein, J.F. Engelhardt, D. Muller, P.J. Lupien and J.M. Wilson. 1994. Successful ex vivo gene therapy directed to liver in a patient with familial hypercholesterolaemia. Nat. Genet. 6:335-341.

6.Kay, M.A., P. Baley, S. Rothenberg, F. Leland, L. Fleming, K. Parker Ponder, T. Liu, M. Finegold, G. Darlington, W. Pokorny and S.L.C. Woo. 1992. Expresson of human $\alpha 1$-antitrypsin in dogs after autologous transplantation of retroviral transduced hepatocytes. Proc. Natl. Acad. Sci. USA 89:89-93.

7.Kay M.A., F. Graham, F. Leland and S.L.C. Woo. 1995. Therapeutic serum concentrations of human alpha-1-antitrypsin after adenovrial mediated gene transfer into mouse hepatocytes. Hepatology 21:815-819.

8.Kay, M.A., C.N. Landen, S. Rothenberg, L.A. Taylor, F. Leland, S. Wiehle, B. Fang, D. Bellinger, M. Finegold, A.R. Thompson, M. Reed, K.M. Brinkhous and S.L.C.Woo. 1994. In vivo hepatic gene therapy: complete albeit transient correction of factor IX deficiency in hemophilia B dogs. Proc. Natl. Acad. Sci. USA 91:2353-2357.

9.Kay, M.A., Q. Li, T. Liu, F. Leland, C. Toman, M. Finegold and S.LC. Woo. 1992. Hepatic gene therapy: persistent expression of human $\alpha 1$-antitrypsin in mice after direct gene delivery in vivo. Hum. Gene Ther. 3:641647.

10.Kay, M.A. and S.L.C. Woo. 1994. Gene therapy for metabolic disorders. Trends Genet. 10:253-257.

11.Li, Q., M.A. Kay, M. Finegold, L.D. Stratford-Perricaudet and S.L.C. Woo. 1993. Assessment of recombinant adenoviral vectors for hepatic gene therapy. Hum. Gene Ther. 4:403-409.

12.Lieber, A., M.T.F.D. Vrancken Peeters, L. Meuse, N. Fausto, J. Perkins and M.A. Kay. 1995. Adenovirus-mediated urokinase gene transfer induces liver regeneration and allows for efficient retrovirus transduction of hepatocytes in vivo. Proc. Natl. Acad. Sci. USA 92:6210-6214.

13.Ponder K., R. P. Dunbar, D.R. Wilson, G. Darlington and S.L.C Woo. 1991. Evaluation of relative promoter strength in primary hepatocytes using optimized lipofection. Hum. Gene Ther. 2:41-52.

14.Ponder, K., S. Gupta, F. Leland, G.Darlington, M. Finegold, J. DeMayo, F.D. Ledley, J.R. Chowdhury and S.L.C. Woo. 1991. Mouse hepatocytes migrate to liver parenchyma and function indefinitely after intrasplenic transplantation. Proc. Natl. Acad. Sci. USA 88:1217-1221.

15.Porteous, D.J. and J.R. Dorin. 1993. How relevant are mouse models for human disease to somatic gene therapy? Trends Biotechnol. 11:173-181.

16.Searle, P.F., B.L. Davison, G.W. Stuart, T.M. Wilkie, G. Norstedt and R.D. Palmiter. 1984. Regulation, linkage, and sequence of mouse metallothionein I and II genes. Mol. Cell. Biol. 4:1221-1230.

17.Smith, T.A., M.G. Mehaffey, D.B. Kayda, J.M. Saunders, S. Yei, B.C. Trapnell, A. McClelland and M. Kaleko. 1993. Aden- ovirus mediated expression of therapeutic plasma levels of human factor IX in mice. Nat. Genet. 5:397-402.

18.Stratford-Perricaudet, L.D., I. Makeh, M. Perricaudet and P. Briand. 1992. Widespread long-term gene transfer to mouse skeletal muscles and heart J. Clin. Invest. 90:626-630.

19.Webber, E.M., J.C. Wu, J.C. Wang, G. Merlino and N. Fausto. 1994. Overexpression of transforming growth factor alpha causes liver enlargement and increased hepatocyte proliferation in transgenic mice. Am. J. Pathol. 145:398-408.

20.Yang, Y., H.C.J. Ertl and J.M. Wilson. 1994. MHC class I-restricted cytotoxic T lymphocytes to viral antigens destroy hepatocytes in mice infected with E1-deleted recombinant adenoviruses. Immunity 1:433-442.

Received 24 May 1995; accepted 2 August 1995.

Address correspondence to:

Mark A. Kay

University of Washington

Division of Medical Genetics

Campus Box 357720/M

1959 N.E. Pacific Street

Seattle, WA 98195, USA

Internet: mkay@u.washington.edu 